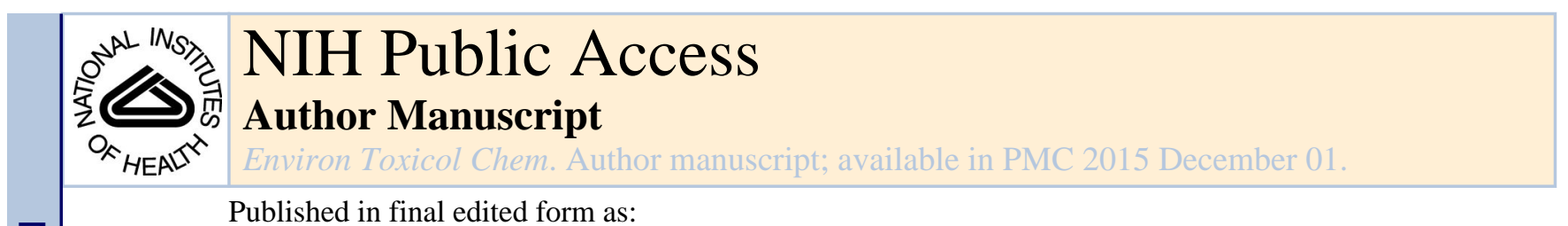

Published in final edited form as:

Environ Toxicol Chem. 2014 December ; 33(12): 2716-2723. doi:10.1002/etc.2705.

\title{
SIZE-DEPENDENT IMPACTS OF SILVER NANOPARTICLES ON THE LIFESPAN, FERTILITY, GROWTH, AND LOCOMOTION OF CAENORHABDITIS ELEGANS
}

\author{
Elizabeth Q. Contreras ${ }^{\dagger}$, Hema L. Puppala ${ }^{\dagger}$, Gabriela Escalera ${ }^{\dagger}$, Weiwei Zhong ${ }^{\ddagger},{ }^{\star}$, and Vicki \\ L. Colvint, ${ }^{*}$ \\ †Department of Chemistry, Rice University, Houston, Texas, USA \\ ‡Department of Biochemistry and Cell Biology, Rice University, Houston, Texas, USA
}

\begin{abstract}
The increased bioavailability of nanoparticles engineered for good dispersion in water may have biological and environmental impacts. To examine this issue, the authors assessed the biological effects in nematodes as they relate to exposure to silver nanoparticles (AgNPs) of different sizes at low (1 mg/L Ag), medium (10 mg/L Ag), and high concentrations (100 mg/L Ag). Over multiple generations, the authors found that the smallest particle, at $2 \mathrm{~nm}$, had a notable impact on nematode fertility. In contrast, the largest particle, at $10 \mathrm{~nm}$, significantly reduced the lifespan of parent nematodes $\left(\mathrm{P}_{0}\right)$ by $28.8 \%$ and over the span of 3 generations $\left(\mathrm{F}_{1}-\mathrm{F}_{3}\right)$. In addition, a computer vision system automatically measured the adverse effects in body length and motility, which were not size-dependent.
\end{abstract}

\section{Keywords}

Caenorhabditis elegans; Silver nanoparticle; Multigenerational; Toxicity; Escherichia coli

\section{INTRODUCTION}

Ecotoxicological studies on degenerative or adaptive behaviors of animal populations may provide the most critical information about adverse effects of trace metals from nanoparticles. There is a reasonable expectation that toxicity may be more pronounced after multiple generations, resulting in either acclimation or toxicity from cumulative damage. In addition to multigenerational studies, measurements of multiple fitness endpoints, such as lifespan, fertility, growth, and locomotion parameters (flex, amplitude, wavelength, and velocity), can further illustrate the biological impacts on animals and off-spring. [1]. Recently, we published a multigenerational study in which we assessed the use of

\footnotetext{
(C) 2014 SETAC

*Address correspondence to colvin@ rice.edu and weiwei.zhong@ rice.edu. All Supplemental Data may be found in the online version of this article.

Tables S1-S7. (64 KB DOC).
} 
Caenorhabditis elegans to study the adverse effects on fitness from exposures to CdSe/ZnS particles (or quantum dots) [1]. We believe the present study to be the first toxicity study with C. elegans that spans 4 generations [1]. In the present study, C. elegans was used as an animal model to assess the toxicity of engineered silver nanoparticles (AgNPs) over 4 generations.

With the short lifespan and large brood size per nematode of C. elegans, multigenerational studies with this species provided a potential screening tool to monitor fitness and health after exposure to toxicants. Nematodes reside in all types of soil and may come into contact with material waste. Potential waste from consumer products makes the testing of biological effects in nematodes relevant. A number of toxicity studies with C. elegans, investigating the impact of many types of nanoparticles, have been reported [1-5]. However, none of the prior work addressed the impacts from exposure to AgNPs over the span of 4 generations.

We continued our investigation using AgNPs, engineered nanoparticles commonly found in consumer products, to further support previous studies with C. elegans [2-5]. The AgNPs were prepared in the laboratory and had no antibacterial properties and no effect on the food source because of the thiolated polyethylene glycol (mPEG-SH) polymer coating that also rendered them water-soluble. Thus, these particular mPEG-SH-coated AgNPs provided the opportunity to examine true particle effects in nematodes as opposed to impacts that are the result of substantial amounts of leaching $\mathrm{Ag}$ ions [6,7].

Because the surface coating was the same, we attribute any toxicity to the different sizes of AgNPs. Size dependence in the mode of toxicity of AgNP has been reported in previous studies [3,8-11]. In fact, particle effect (or size dependence) is a common mode of toxicity in vitro and in vivo and occurs from the actual presence of a hard chafing material physically embedded within the organism that causes significant structural damage and infections without remedy $[12,13]$. Some studies showed that larger AgNPs $(50 \mathrm{~nm})$ in $C$. elegans caused irreparable epidermal abrasions and infections and eventually death $[1,2,7,8,10]$, whereas other studies showed how smaller particles (of $10 \mathrm{~nm}$ or less) can easily transfer through nematode embryonic cell walls, tissues, and organs, causing offspring death $[3,8-11]$.

Because nanoparticles can be introduced easily into the environment, the present multigenerational study becomes more critical for sublethal concentrations. In the present study, we evaluated the biological effects of AgNPs in C. elegans for 4 generations. When AgNPs were introduced over multiple generations, adverse effects on nematode lifespan and fertility were size-dependent; in terms of developmental and neurological measurements, however, size dependence was not noted, suggesting a different toxicity mechanism.

\section{MATERIALS AND METHODS}

\section{Silver nanoparticle preparation and characterization}

To control for size and stability, AgNPs were prepared as recently described with $\mathrm{AgClO}_{4}$ and an oleic acid coating $[14,15]$. Briefly, for monodispersed $\mathrm{AgNPs}, \mathrm{AgClO}_{4}$ was reduced by oleylamine at varying temperatures to produce different sizes and coated in situ with 
oleic acid for stability. These materials were made water soluble by coating with mPEG-SH $(\mathrm{Mn}=5000$; Sigma $)$ through a ligand exchange reaction. After a phase transfer into water, the mPEG-SH surface coating limited the dissolution of ionic silver.

The size and chemical composition of AgNPs were carefully measured using several characterization tools (Figure 1). The silver core diameter was determined by transmission electron microscopy (Jeol 2010 TEM). Dynamic light scattering (Malvern Zetasizer NanoZS) was used to characterize the hydrodynamic diameter and zeta potential of the nanoparticles in solution (Figure 1). The silver ion concentration was determined by inductively coupled plasma-mass spectrometry (ICP-MS). All concentrations were based on milligrams of silver ion in solution. Three AgNP treatments at the sublethal concentrations of $1 \mathrm{mg} \mathrm{Ag} / \mathrm{L}, 10 \mathrm{mg} \mathrm{Ag} / \mathrm{L}$, and $100 \mathrm{mg} \mathrm{Ag} / \mathrm{L}$ were set. All reagents were of analytical grade and were supplied by Sigma Aldrich.

\section{C. elegans maintenance}

The Caenorhabditis Genetics Center (at the University of Minnesota, St. Paul, MN, USA) provided the wild-type $\mathrm{N} 2$ strain, which was maintained in 24 -well plates at $20^{\circ} \mathrm{C}$ on $1 \mathrm{~mL}$ of nematode growth medium (NGM)-agar and a bacterial lawn of Escherichia coli OP50 as food following standard protocols [16]. To obtain a synchronized population, gravid hermaphrodites were collected and treated with hypochlorite [16]. Nematode populations were synchronized and allowed to mature into the fourth larval (L4) stage for assessment.

\section{Assessment of E. coli viability}

To measure the impact of AgNPs on OP50 E. coli, the food source for C. elegans, AgNPs were added to the bacterial lawn as described previously, except that no C. elegans were placed on the lawn [15,17]. In 24-well plates maintained at $20^{\circ} \mathrm{C}$, a $30-\mu \mathrm{L}$ treatment for each sample was added to the bacterial lawn for $24 \mathrm{~h}$ for homogenous exposure. After the inoculation time, the bacteria were washed with $1 \mathrm{~mL}$ sterile $\mathrm{H}_{2} \mathrm{O}$ to make serial dilutions. To a 6-cm LB plate, $20 \mu \mathrm{L}$ of each dilution was added, and the plates were incubated overnight at $37^{\circ} \mathrm{C}$. Bacterial viability was determined by counting the colonies and calculating the initial concentration of live bacteria in solution.

In a preliminary concentration range-finding study (results shown in Figure 2), equivalent amounts of ionic silver ( $\mathrm{Ag}+$ ), as a reference toxicant from $\mathrm{AgNO}_{3}$ and $\mathrm{AgClO}_{4}$ solutions, were also assessed in E. coli. Ionic silver has antibacterial properties at extremely low concentrations, which would induce bacterial death (and then nematode death by starvation).

\section{Multigenerational toxicity study}

Experiments were carried out in 24-well plates. Each well consisted of $1 \mathrm{~mL}$ NGM-agar and was seeded with $10 \mu \mathrm{L}$ of fresh overnight-cultured E. coli OP50 for $3 \mathrm{~d}$ to form the bacterial lawn. To the surface of each well, $30 \mu \mathrm{L}$ of AgNP solution was aliquoted onto a dry, solid agar surface using a wide range of exposure concentrations $(1-100 \mathrm{mg} / \mathrm{L})$ that have been shown to be successfully internalized by feeding [1]. After approximately $30 \mathrm{~min}$ at $20^{\circ} \mathrm{C}, 1$ L4 stage nematode (parent $\left[\mathrm{P}_{0}\right]$ ) was randomly selected, placed into each well, and 
cultivated in $20^{\circ} \mathrm{C}$ incubators. We chose to expose $C$. elegans on agar plates to reduce stress and to provide food.

Parent nematodes $\left(\mathrm{P}_{0}\right)$ were continuously treated for the entire lifespan from L4 to death. During the lifespan of $\mathrm{P}_{0}$, its progeny and subsequent generations $\left(\mathrm{F}_{1}, \mathrm{~F}_{2}\right.$, and $\left.\mathrm{F}_{3}\right)$ were the first to be exposed to AgNPs beginning in the egg stage. In subsequent generations, $C$. elegans L4s were randomly selected from first-day progeny. Every $24 \mathrm{~h}$ during treatment, all animals were transferred to freshly dosed wells for continuous exposure. Only nematodes that reached adulthood by day 4 were measured.

\section{Quantification of internalized silver}

The silver concentration within N2 nematodes (ng Ag/worm), as shown in Figure 3, was measured by ICP-MS (Perkin Elmer, ELAN9000).

Quantification included collecting 100 young adult (L4) nematodes and washing them to remove bacteria and excess chemicals. The nematodes were placed in preweighed glass tubes and $1 \mathrm{~mL}$ of $70 \% \mathrm{HNO}_{3}$, followed by heat digestion in a block heater at $90{ }^{\circ} \mathrm{C}$ for $4 \mathrm{~h}$, and left overnight to cool. The solution was then diluted with ultrapure water to achieve a final acid concentration of $1 \%$.

\section{Lifespan and fertility measurement}

A dissecting microscope (Unitron) was used to record fertility and lifespan. Fertility was measured by counting the number of L4 offspring per nematode (brood size) $3 \mathrm{~d}$ after hatching. An untreated wild-type N2 nematode will produce approximately 300 offspring in $4 \mathrm{~d}$. After the addition of $30 \mu \mathrm{L}$ of AgNP solution to each well of a 24-well plate, a single L4 nematode was placed in each well. After every $24 \mathrm{~h}$, nematodes were moved to a freshly dosed well on the next row of the same plate to allow the nematode to lay eggs and for continuous exposure to AgNP for its entire lifespan. Moving the nematodes every day controlled the number of eggs in each well to avoid depleting the bacterial lawn after the eggs hatched. The experiment was repeated 3 times for each treatment.

Lifespan consisted of the number of days between egg and death of the nematode. Each well was freshly dosed daily before adding a population of $10 \mathrm{~L} 4$ nematodes into each well. Changes in population were carefully recorded daily, and death of a nematode was noted after a gentle tap resulted in no movement. Nematodes were continuously exposed to AgNP by moving the population into a freshly dosed well every $24 \mathrm{~h}$. This also provided sufficient amounts of food to avoid starvation. The experiment was repeated twice.

\section{Body length and locomotive behavior}

Sublethal concentrations of AgNPs may cause adverse developmental and neurological responses. Body length and locomotive behavior were measured at a constant temperature of $20^{\circ} \mathrm{C}$ by a worm tracker built in our laboratory. The worm tracker consisted of a dissecting microscope (Unitron) with a motorized stage (Prior) and a Firewire camera (Fire-I; Unibrain) [18]. 
Four days after hatching, first-day adult nematodes were randomly chosen [18]. On a 10-cm NGM-agar plate with fresh OP50 E. coli, a single nematode was tracked and recorded in a 4-min video. From the video, body length and 4 locomotive behaviors (flex, amplitude, wavelength, and velocity) were quantitatively analyzed. For each treatment, 10 individual nematodes were tracked. The experiment was repeated twice.

\section{Statistical analysis of variance}

For every fitness endpoint, untreated nematodes were measured for each generation for comparison with nematodes exposed to AgNPs. One-way analysis of variance (ANOVA) post hoc Tukey's test at a 99\% confidence interval was calculated by using OrginPro 8.5.1 (OriginLab) on all samples compared with untreated controls (Supplemental Data, Tables S1-S7).

In Figures 4-10, each vertical bar represents the mean difference against the untreated control (ANOVA and post hoc Tukey test with 99\% confidence interval). If the interval excluded 0 , then the difference was considered significant (red marker) for that pairwise comparison. The bolded vertical bars in Figures 4-10 represent no data, as F3 nematodes did not survive exposure.

Figures 7-10 show measurements of neurological behaviors (flex, amplitude, wavelength, and velocity) for multigenerations after treatment at low $(1 \mathrm{mg} \mathrm{Ag} / \mathrm{L})$, medium $(10 \mathrm{mg}$ $\mathrm{Ag} / \mathrm{L})$, and high (100 mg Ag/L) concentrations. An A represents multigenerational data in which the effect in subsequent generations is different from that of the first generation. An X indicates continual adverse effects over multiple generations.

\section{RESULTS AND DISCUSSION}

In the present study, C. elegans were exposed to 3 different AgNPs with diameters from 1 $\mathrm{nm}$ to $10 \mathrm{~nm}$, small and highly monodispersed particles (Figure 1). Before nematodes were treated, bacterial lawns were dosed with freshly prepared AgNPs to test particle stability.

\section{Effects of ionic silver versus AgNP on the growth of $E$. coli}

The preliminary concentration range-finding study (Figure 2) showed that extremely low concentrations of Ag salt solutions were acutely toxic to the food source. In the present study, Ag ions are indisputably antibacterial, as has been shown in the literature [17]. The well-known antibacterial property of silver has been exploited in medicinal textiles and in many other consumer products [19]. According to the literature, free ion dissociation from AgNPs is acutely toxic and can cause ionic gradient changes across membranes and malfunctioning organelles, as well as disruption of peptide function because of oxidative stress [5-7,9]. In the present study, AgNP treatments were set at $1 \mathrm{mg} \mathrm{Ag} / \mathrm{L}, 10 \mathrm{mg} \mathrm{Ag/L}$, and $100 \mathrm{mg} \mathrm{Ag} / \mathrm{L}$ to obtain a large test range. Any dissolution of ionic silver from AgNPs would destroy the bacterial lawn and cause secondary adverse effects in C. elegans, from developmental defects to death by starvation [20].

The AgNPs with an mPEG-SH coating that we used had no effect on $E$. coli and nematode food source (Table 1). Table 1 shows that at the highest exposure concentration of $100 \mathrm{mg}$ 
$\mathrm{Ag} / \mathrm{L}$, E. coli remained viable with no significant changes compared with untreated control (Table 1). The absence of a bactericidal effect throughout the experiment also shows the stability of AgNPs. The polymer surface coating in fact decreased dissolution, and any adverse effect from exposure to AgNPs was not from starvation.

\section{AgNP uptake and quantification of $\mathrm{Ag}+$}

Caenorhabditis elegans do not discern between bacteria and nanoparticles of $5 \mu \mathrm{m}$ or less when feeding [21]. Contreras et al. [1] showed that the main route of exposure was through the digestive tract. Total silver body burden was assessed quantitatively by ICP-optical emission spectrometry (Figure 3). The exposure concentration in nematodes exposed since the egg stage (F1) was $100 \mathrm{mg} \mathrm{Ag} / \mathrm{L}$. A lesser amount of $\mathrm{Ag}+$ was internalized in C. elegans exposed to Ag particles of $2 \mathrm{~nm}$ compared with larger particles of $5 \mathrm{~nm}$ and $10 \mathrm{~nm}$ (Figure 3). For 2-nm AgNP exposures, the internalized silver concentration was $1.30 \pm 0.2 \mathrm{ng} /$ nematode. The Ag ion concentrations were $1.80 \pm 0.1 \mathrm{ng} /$ nematode for nematodes exposed to 5-nm particles and $1.84 \pm 0.2 \mathrm{ng} /$ nematode for nematodes exposed to $10-\mathrm{nm}$ particles. This range of Ag ion concentrations in C. elegans was in agreement with that found by Choi et al. [22] who treated zebrafish with $120 \mathrm{mg} \mathrm{Ag} / \mathrm{L} \mathrm{AgNP}$ and measured a silver concentration of $2.4 \mathrm{ng} \mathrm{Ag} / \mathrm{liver}$. We speculate that a smaller diameter increased particle mobility out of the body or into eggs, [3] whereas larger sized particles accumulated longer inside the body. Additional biokinetic studies that address the rates of uptake and depuration are in progress.

\section{Multigenerational toxicity response}

Lifespan assay-The cumulative adverse effect on mean lifespan was size-dependent at $100 \mathrm{mg} \mathrm{Ag/L} \mathrm{(Figure} \mathrm{4).} \mathrm{For} \mathrm{untreated} \mathrm{C.} \mathrm{elegans,} \mathrm{the} \mathrm{mean} \mathrm{lifespan} \mathrm{and} \mathrm{reference} \mathrm{was} 14.2$ d [23]. At $100 \mathrm{mg} / \mathrm{L}, \mathrm{AgNPs}$ of 2-nm and 5-nm diameter caused no significant change in parent $\left(\mathrm{P}_{0}\right)$ lifespan (Figure 4A and B). In contrast, at $100 \mathrm{mg} / \mathrm{L}, 10-\mathrm{nm}$ AgNPs caused the most adverse effect: they decreased the mean lifespan for $\mathrm{P}_{0}$ nematodes by $28.8 \%$; and over the span of 3 generations, $10-\mathrm{nm} \mathrm{Ag}$ particles continued to significantly decrease $(p<0.01)$ mean lifespan compared with smaller sized AgNPs (Figure 4C).

We speculate from information in the literature that particles larger than $10 \mathrm{~nm}$ can also cause exogenous stress [2,8]. Kim et al. [2] introduced larger particles of 50.6-nm citratecoated AgNPs to C. elegans by feeding and showed by numerous scanning electron microscopy images that AgNPs fractured the epidermis, resulting in death. The cuticle of $C$. elegans became physically rigid from exposure to AgNPs, which prevented molting and caused bursting, becoming lethal [2]. No images were taken in the present study to further support the work of Kim et al. [2]; instead, we focused on a novel screening method to assess quickly and quantitatively the biological impacts of nanoparticles in nematodes using an automated Worm Tracker and a compound microscope.

For subsequent generations, all $\mathrm{Ag}$ particles in the present study caused a significant decrease in mean lifespan (Figure 4). For example, at $100 \mathrm{mg} \mathrm{Ag} / \mathrm{L}$, when the impact at different sizes was compared, 10-nm AgNPs reduced lifespan in more generations, including $\mathrm{P}_{0}$, than 5-nm particles (Figure $4 \mathrm{~B}$ and $\mathrm{C}$ ). For first-generation progeny $\left(\mathrm{F}_{1}\right)$, the mean 
lifespan of nematodes exposed to 10-nm AgNPs (100 mg/L) continued to decrease significantly ( $p<0.01$ ), by 58.7\%, whereas exposure to 2-nm and 5-nm AgNPs decreased mean lifespan by $30.8 \%$ and $34.6 \%$, respectively (Figure 4 ). For second-generation progeny $\left(\mathrm{F}_{2}\right)$, AgNPs of $2 \mathrm{~nm}$ and $5 \mathrm{~nm}$ reduced $\mathrm{F}_{2}$ mean lifespan by $21.5 \%$ and $49 \%$, respectively (Figure 4). Also at $100 \mathrm{mg} \mathrm{Ag} / \mathrm{L}$, the change in mean lifespan for 5-nm AgNP for $\mathrm{F}_{1}$ and $\mathrm{F}_{2}$ was much more significant than for 2-nm particles, whereas the $\mathrm{F}_{2}$ results from $5 \mathrm{~nm}$-AgNPs at $100 \mathrm{mg} / \mathrm{L}$ (49\% reduced mean lifespan) was comparable to results from $10-\mathrm{nm}$ particles (52\% reduced mean lifespan). However, 10 -nm particles adversely effected $\mathrm{P}_{0}$ and $\mathrm{F}_{1}$ generations faster and more significantly than other sizes (Figure 4C).

After 3 generations $\left(\mathrm{F}_{3}\right)$ of chronic exposure to $100 \mathrm{mg} / \mathrm{L}, \mathrm{AgNPs}$ caused a significant decrease in population with any treatment of different-sized AgNPs (Figure 4, red lines). We speculate that AgNPs lethally damaged the exterior cuticle, as recently described by Kim et al. [2,21]. In addition to exogenous stress to the epidermis [2], endogenous stress from internalized smaller AgNPs accumulated over multiple generations. Smaller nanoparticles would have increased bioavailability, because they are easier to absorb than larger nanoparticles and translocate more easily within and between cells and tissues in nematodes, resulting in higher toxicity as shown by parent sterility or death $[10,11]$ or in offspring developmental delay or death [4].

Fertility assay-In contrast to lifespan, 2-nm AgNPs caused the greatest adverse effect on fertility over 3 generations, in comparison with larger sized AgNPs (Figure 5A). An untreated (control) single worm has approximately 300 offspring over its lifetime in the span of $4 \mathrm{~d}$ [23]. At $10 \mathrm{mg} \mathrm{Ag} / \mathrm{L}$, the adverse effect on C. elegans brood size was size-dependent. For example, the smallest (2-nm) AgNPs at $10 \mathrm{mg} / \mathrm{L}$ significantly decreased $(p<0.01)$ all nematode populations for $\mathrm{P}_{0}, \mathrm{~F}_{1}$, and $\mathrm{F}_{2}$ generations to an average of 185 nematodes (Figure $5 \mathrm{~A})$. For 5 -nm AgNPs at $10 \mathrm{mg} / \mathrm{L}$, change in brood size was smaller, and the number of $\mathrm{F}_{2}$ surviving offspring was significantly decreased $(p<0.01)$ to 197 nematodes (Figure 5B). Lastly, $10-\mathrm{nm}$ AgNPs at $10 \mathrm{mg} / \mathrm{L}$ did not adversely affect brood size for 3 generations (Figure 5C). This is in agreement with Meyer et al. [3], who illustrated how smaller AgNPs transferred past embryonic cell walls, causing transgenerational toxicity, developmental delays, or death in progeny.

For this reason, smaller nanoparticles have also been found to be more toxic than larger nanoparticles because of increased total surface area, which is especially true for $\mathrm{ZnO}$ particles [10]. Greater total surface area allows for increased reactivity that can damage proteins and organelles in vivo. Also, extensive damage occurs when smaller nanoparticles diffuse through the transmembrane pore cells and embryos [24]. Lee et al. described how, once internalized, small-sized AgNPs can aggregate with other nanoparticles into clots, becoming lethal [24]. This intracellular clotting prevented AgNPs from diffusing out, which caused developmental delays, deformities, and offspring death in zebrafish [24]. In addition to particle effect, toxicity was also dose-dependent from $0 \mathrm{mg} \mathrm{Ag} / \mathrm{L}$ to $100 \mathrm{mg} \mathrm{Ag} / \mathrm{L}$, which caused an increase in adverse effects.

At $100 \mathrm{mg} \mathrm{Ag} / \mathrm{L}$, reduced brood size for 3 generations was cumulative and size-dependent (Figure 5). For smaller particle sizes, $2 \mathrm{~nm}$ caused brood size to decrease from $56.8 \%$ for $\mathrm{P}_{0}$ 
to $98.9 \%$ by $\mathrm{F}_{2}$ at a decrease rate of 64 nematodes/generation (Figure 5A). For 5-nm AgNP, brood size decreased at a rate of 77 nematodes/generation (Figure 5B). Exposure to the largest AgNP $(10 \mathrm{~nm})$ caused a significant decrease $(p<0.01)$ in brood size of $26.4 \%$ for $\mathrm{P}_{0}$ to $98.2 \%$ by $\mathrm{F}_{2}$, with a decrease rate of 108 nematodes/generation (Figure 5C). For all AgNPs tested, the $F_{2}$ brood size was similar, and $F_{3}$ extinction occurred because of either low or no sample size (Figure 5, $\mathrm{F}_{3}$ red lines). We speculate that these size-dependent toxicities for both lifespan and brood size accumulated with each generation, leading to serious $\mathrm{F}_{3}$ mortality rates. In the present study, parameters such as lifespan and fertility gave more distinct and linear results from AgNP exposure than growth and locomotion [25].

Growth assay-When exposed to 5-nm and 10-nm AgNPs, the body length of first-day adults was adversely affected at high concentrations, but these adults acclimated at low exposure concentrations (Figure 6B and C). For example, acclimation at the low exposure concentration of $1 \mathrm{mg} \mathrm{Ag} / \mathrm{L}$ occurred when $\mathrm{F}_{1}$ progeny body length was significantly greater $(p<0.01)$ than average; but by generation $\mathrm{F}_{2}$, body length had returned to normal (Figure $6 \mathrm{~B}$ and $\mathrm{C}$ ). Another example of physiological acclimation occurred at $10 \mathrm{mg} \mathrm{Ag} / \mathrm{L}: 5-\mathrm{nm}$ AgNPs caused shorter body lengths in $\mathrm{F}_{2}$ progeny, but length had returned to normal by generation $\mathrm{F}_{3}$ compared with untreated controls (Figure 6B). However, cumulative adverse effects, at the high concentration of $100 \mathrm{mg} \mathrm{Ag} / \mathrm{L}$, occurred when multiple generations were chronically exposed to 2-nm, 5-nm, and 10-nm AgNPs, which increasingly caused developmental delays and stunted the growth of offspring (Figure 6) [3,11]. To summarize, the adverse effect on growth (body length) was not size-dependent, as with lifespan and fertility.

Locomotion assay-In the same way, adverse effects on locomotion (flex, amplitude, wavelength, and velocity) were not size-dependent (Figures 7-10). With the exception of 1 amplitude endpoint for 2-nm AgNPs, at the highest sublethal concentration $(100 \mathrm{mg} \mathrm{Ag} / \mathrm{L})$ for all sizes, significant impacts $(p<0.01)$ and cumulative adverse effects on amplitude, wavelength, and velocity occurred, with no acclimation (Figures $8-10$, denoted as $\mathrm{X}$ ). That is, nematodes exposed for multiple generations to the highest exposure concentration of 100 $\mathrm{mg} \mathrm{Ag} / \mathrm{L}$ had decreased body movement and forward trajectory. These sublethal impediments to locomotion behaviors could result from adverse epidermal damage to the cuticle by AgNPs, limiting movement, or from neurotoxicity [2].

In contrast, at lower exposure concentrations of $1 \mathrm{mg} \mathrm{Ag} / \mathrm{L}$ and $10 \mathrm{mg} \mathrm{Ag} / \mathrm{L}$ of 2-nm AgNPs, acclimation in nematode progeny occurred with all locomotion endpoints measured (denoted as A in Figures 7-10), except for amplitude (Figure 8A). Specifically, acclimation occurred when $\mathrm{P}_{0}$ locomotion became impaired, but then returned to normal in progeny. For example, when the flex parameter (number of times that the body bends) was monitored, $\mathrm{F}_{1}$ progeny were seen to acclimate, and flex behavior returned to normal compared with untreated nematodes (Figure 7A).

When nematodes were exposed to 5-nm AgNPs, the amplitude cumulatively worsened in a dose-dependent manner in $F_{2}$ and $F_{3}$ generations (Figure $8 \mathrm{~B}$ ). In contrast, at $1 \mathrm{mg} \mathrm{Ag} / \mathrm{L}$, nematodes acclimated by $\mathrm{F}_{3}$ to $\mathrm{AgNP}$ chronic exposures, but at $10 \mathrm{mg} \mathrm{Ag} / \mathrm{L}$, the opposite was true (Figure 8B). At $10 \mathrm{mg} \mathrm{Ag} / \mathrm{L}$, amplitude began to decrease after 2 generations of 
chronic exposure, as with $100 \mathrm{mg} \mathrm{Ag/L} \mathrm{(Figure} \mathrm{8B).} \mathrm{Another} \mathrm{example} \mathrm{of} \mathrm{dose-dependent}$ adverse effects on fitness occurred with velocity (Figure 10).

It is possible that some element of randomness occurred in these endpoints, but the data also suggest the possibility of long-term cumulative adverse effects after exposure for multiple generations to water-soluble nanoparticles with increased bioavailability and health risks. Ultimately, toxicity in $C$. elegans can have a dire effect on fitness, the food web, and the ecosystem.

\section{CONCLUSIONS}

In the present study, we introduced a potentially fast screening method to quantitatively measure a number of fitness endpoints in C. elegans that were sensitive to AgNP exposures. For 4 generations, $C$. elegans and E. coli were continuously exposed to AgNPs of 3 different sizes, $2 \mathrm{~nm}, 5 \mathrm{~nm}$, and 10. The AgNPs caused no adverse effects on E. coli or on the food of C. elegans, demonstrating no immediate bactericidal effects from leaching Ag ions [15]. However, these nanoparticles had a size-dependent effect on lifespan and fertility of $C$. elegans after exposure for multiple generations. At $100 \mathrm{mg} \mathrm{Ag/L,} \mathrm{the} \mathrm{largest} \mathrm{diameter}$ AgNPs significantly shortened the lifespan of $C$. elegans, causing the most lethal damage, whereas the smallest diameter AgNPs significantly affected fertility. When growth and neurodegenerative endpoints were measured, AgNPs had some adverse effects that were not size-dependent. Instead, nematodes acclimated at lower concentrations but suffered cumulative damage at higher exposure concentrations.

The results from the present study are far from conclusive, and future research should consider a variety of assays, from physiological endpoints to genotoxicity, to elucidate the mechanism of toxicity. For example, to defend against lethal stresses and to acclimate to a toxic environment, $C$. elegans have the ability to produce metal-binding proteins, such as metallothionein, to purge their bodies of trace metal contaminates. They can also increase protein scavengers, such as glutathione peroxidase and superoxide dismutase, to remove stress-induced reactive oxygen species and decrease internal damage [26]. Measuring proteins is a common method of monitoring environmental threats and issues. Another coping mechanism consists of regulating the trade-off between fertility and lifespan, for example, to maintain [4,27]. The fitness endpoints measured in the present study, along with future nanobiotoxicology studies that are under way, can further unravel complex modes of toxicity.

\section{Supplementary Material}

Refer to Web version on PubMed Central for supplementary material.

\section{Acknowledgment}

We thank M.L. Derkowska, W. Duncan Wadsworth, and B. Aleman-Meza for their assistance in various aspects of the present research. We also thank the Caenorhabditis Genetic Center for strains. E.Q. Contreras was supported by the Center for Biological and Environmental Nanotechnology (NSF EEC 0647452) and by US Environmental Protection Agency grant RD834557501-0 to Rice University. Additional funding was provided by National Institutes of Health grant R00HG004724 and the Kinship Foundation through a Searle Scholars grant to W. Zhong. 


\section{REFERENCES}

1. Contreras EQ, Cho M, Zhu H, Puppala HL, Escalera G, Zhong W, Colvin VL. Toxicity of quantum dots and cadmium salt to Caenorhabditis elegans after multigenerational exposure. Environ Sci Technol. 2012; 47:1148-1154. [PubMed: 23241207]

2. Kim SW, Nam S-H, An Y-J. Interaction of silver nanoparticles with biological surfaces of Caenorhabditis elegans. Ecotoxicol Environ Saf. 2012; 77:64-70. [PubMed: 22078113]

3. Meyer JN, Lord CA, Yang XY, Turner EA, Badireddy AR, Marinakos SM, Chilkoti A, Wiesner MR, Auffan M. Intracellular uptake and associated toxicity of silver nanoparticles in Caenorhabditis elegans. Aquat Toxicol. 2010; 100:140-150. [PubMed: 20708279]

4. Roh J-Y, Sim SJ, Yi J, Park K, Chung KH, Ryu D-Y, Choi J. Ecotoxicity of silver nanoparticles on the soil nematode Caenorhabditis elegans using functional ecotoxicogenomics. Environ Sci Technol. 2009; 43:3933-3940. [PubMed: 19544910]

5. Yang X, Gondikas AP, Marinakos SM, Auffan M, Liu J, Hsu-Kim H, Meyer JN. Mechanism of silver nanoparticle toxicity is dependent on dissolved silver and surface coating in Caenorhabditis elegans. Environ Sci Technol. 2011; 46:1119-1127. [PubMed: 22148238]

6. Auffan M, Rose J, Bottero J-Y, Lowry GV, Jolivet J-P, Wiesner MR. Towards a definition of inorganic nanoparticles from an environmental, health and safety perspective. Nat Nano. 2009; 4:634-641.

7. Kawata K, Osawa M, Okabe S. In vitro toxicity of silver nanoparticles at noncytotoxic doses to HepG2 human hepatoma cells. Environ Sci Technol. 2009; 43:6046-6051. [PubMed: 19731716]

8. Bowman CR, Bailey FC, Elrod-Erickson M, Neigh AM, Otter RR. Effects of silver nanoparticles on zebrafish (Danio rerio) and Escherichia coli (ATCC 25922): A comparison of toxicity based on total surface area versus mass concentration of particles in a model eukaryotic and prokaryotic system. Environ Toxicol Chem. 2012; 31:1793-1800. [PubMed: 22573570]

9. Oberdorster G, Oberdorster E, Oberdorster J. Nanotoxicology: An emerging discipline evolving from studies of ultrafine particles. Environ Health Perspect. 2005; 113:823-839. [PubMed: 16002369]

10. Ma H, Kabengi NJ, Bertsch PM, Unrine JM, Glenn TC, Williams PL. Comparative phototoxicity of nanoparticulate and bulk $\mathrm{ZnO}$ to a free-living nematode Caenorhabditis elegans: The importance of illumination mode and primary particle size. Environ Pollut. 2011; 159:1473-1480. [PubMed: 21470728]

11. Wang $\mathrm{HH}$, Wick RL, Xing BS. Toxicity of nanoparticulate and bulk $\mathrm{ZnO}, \mathrm{Al}_{2} \mathrm{O}_{3}$ and $\mathrm{TiO}_{2}$ to the nematode Caenorhabditis elegans. Environ Pollut. 2009; 157:1171-1177. [PubMed: 19081167]

12. Morones JR, Elechiguerra JL, Camacho A, Holt K, Kouri JB, Ramírez JT, Yacaman MJ. The bactericidal effect of silver nanoparticles. Nanotechnology. 2005; 16:2346. [PubMed: 20818017]

13. Mueller NC, Nowack B. Exposure modeling of engineered nanoparticles in the environment. Environ Sci Technol. 2008; 42:4447-4453. [PubMed: 18605569]

14. Hiramatsu H, Osterloh FE. A simple large-scale synthesis of nearly monodisperse gold and silver nanoparticles with adjustable sizes and with exchangeable surfactants. Chem Mater. 2004; 16:2509-2511.

15. Xiu, Z-m; Zhang, Q-B.; Puppala, HL.; Colvin, VL.; Alvarez, PJJ. Negligible particle-specific antibacterial activity of silver nanoparticles. Nano Lett. 2012; 12:4271-4275. [PubMed: 22765771]

16. Stiernagle T. Maintenance of C. elegans. WormBook: The Online Review of C. elegans Biology. Available from http://www.wormbook.org.

17. Kim JS, Kuk E, Yu KN, Kim J-H, Park SJ, Lee HJ, Kim SH, Park YK, Park YH, Hwang C-Y, Kim Y-K, Lee Y-S, Jeong DH, Cho M-H. Antimicrobial effects of silver nanoparticles. Nanomed Nanotechnol. 2007; 3:95-101.

18. Cronin C, Mendel J, Mukhtar S, Kim Y-M, Stirbl R, Bruck J, Sternberg P. An automated system for measuring parameters of nematode sinusoidal movement. BMC Genet. 2005; 6:5. [PubMed: 15698479]

19. Tolaymat TM, El Badawy AM, Genaidy A, Scheckel KG, Luxton TP, Suidan M. An evidencebased environmental perspective of manufactured silver nanoparticle in syntheses and 
applications: A systematic review and critical appraisal of peer-reviewed scientific papers. Sci Total Environ. 2010; 408:999-1006. [PubMed: 19945151]

20. Boyd WA, Cole RD, Anderson GL, Williams PL. The effects of metals and food availability on the behavior of Caenorhabditis elegans. Environ Toxicol Chem. 2003; 22:3049-3055. [PubMed: 14713049]

21. Donkin SG, Dusenbery DB. A soil toxicity test using the nematode Caenorhabditis elegans and an effective method of recovery. Arch Environ Contam Toxicol. 1993; 25:145-151.

22. Choi JE, Kim S, Ahn JH, Youn P, Kang JS, Park K, Yi J, Ryu D-Y. Induction of oxidative stress and apoptosis by silver nanoparticles in the liver of adult zebrafish. Aquat Toxicol. 2010; 100:151-159. [PubMed: 20060176]

23. Wood, WB. The Nematode Caenorhabditis elegans. Cold Spring Harbor, NY, USA: Cold Spring Harbor Laboratory Press; 1988.

24. Lee KJ, Browning LM, Nallathamby PD, Desai T, Cherukuri PK, Xu X-HN. In vivo quantitative study of sized-dependent transport and toxicity of single silver nanoparticles using zebrafish embryos. Chem Res Toxicol. 2012; 25:1029-1046. [PubMed: 22486336]

25. Roh J-Y, Park Y-K, Park K, Choi J. Ecotoxicological investigation of $\mathrm{CeO}_{2}$ and $\mathrm{TiO}_{2}$ nanoparticles on the soil nematode Caenorhabditis elegans using gene expression, growth, fertility, and survival as endpoints. Environ Toxicol Pharmacol. 2010; 29:167-172. [PubMed: 21787599]

26. Martinez-Finley EF, Aschner M. Revelations from the nematode Caenorhabditis elegans on the complex interplay of metal toxicological mechanisms. J Toxicol. 2011

27. Motola DL, Cummins CL, Rottiers V, Sharma KK, Li T, Li Y, Suino-Powell K, Xu HE, Auchus RJ, Antebi A, Mangelsdorf DJ. Identification of ligands for DAF-12 that govern Dauer formation and reproduction in C. elegans. Cell. 2006; 124:1209-1223. [PubMed: 16529801] 

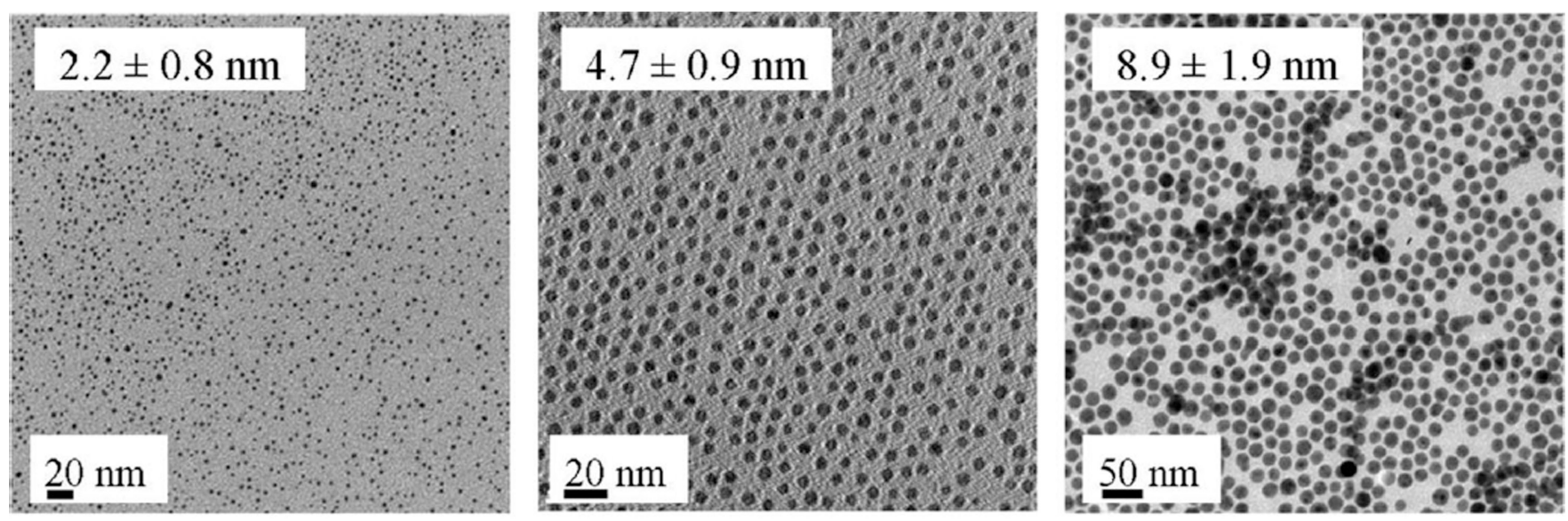

\begin{tabular}{llll}
\hline Parameters & $2 \mathrm{~nm}$ & $5 \mathrm{~nm}$ & $10 \mathrm{~nm}$ \\
\hline Core diameter $(\mathrm{nm})$ & $2.2 \pm 0.8$ & $4.7 \pm 0.9$ & $8.9 \pm 1.9$ \\
Surface area $\left(\mathrm{nm}^{2}\right)$ & 15.2 & 69.5 & 249.1 \\
DLS $_{\text {aq }}(\mathrm{nm})$ & $22.1 \pm 3.5$ & $26.5 \pm 4.1$ & $35.5 \pm 2.1$ \\
\hline
\end{tabular}

Figure 1.

Silver nanoparticle (AgNP) characterization (A) of 2-nm, (B) 5-nm, and (C) 10-nm silver particles. The core diameter was determined from transmission electron microscopy (TEM) images coated with thiolated methoxy-polyethylene glycol (mPEG-SH; nonaggregated, 0.12 $\mathrm{mV}$ ). From this, the surface area in $\mathrm{nm}^{2}$ was calculated. The addition of mPEG-SH via a ligand exchange was measured by dynamic light scattering (DLS) in the organic and aqueous (aq) solutions. 


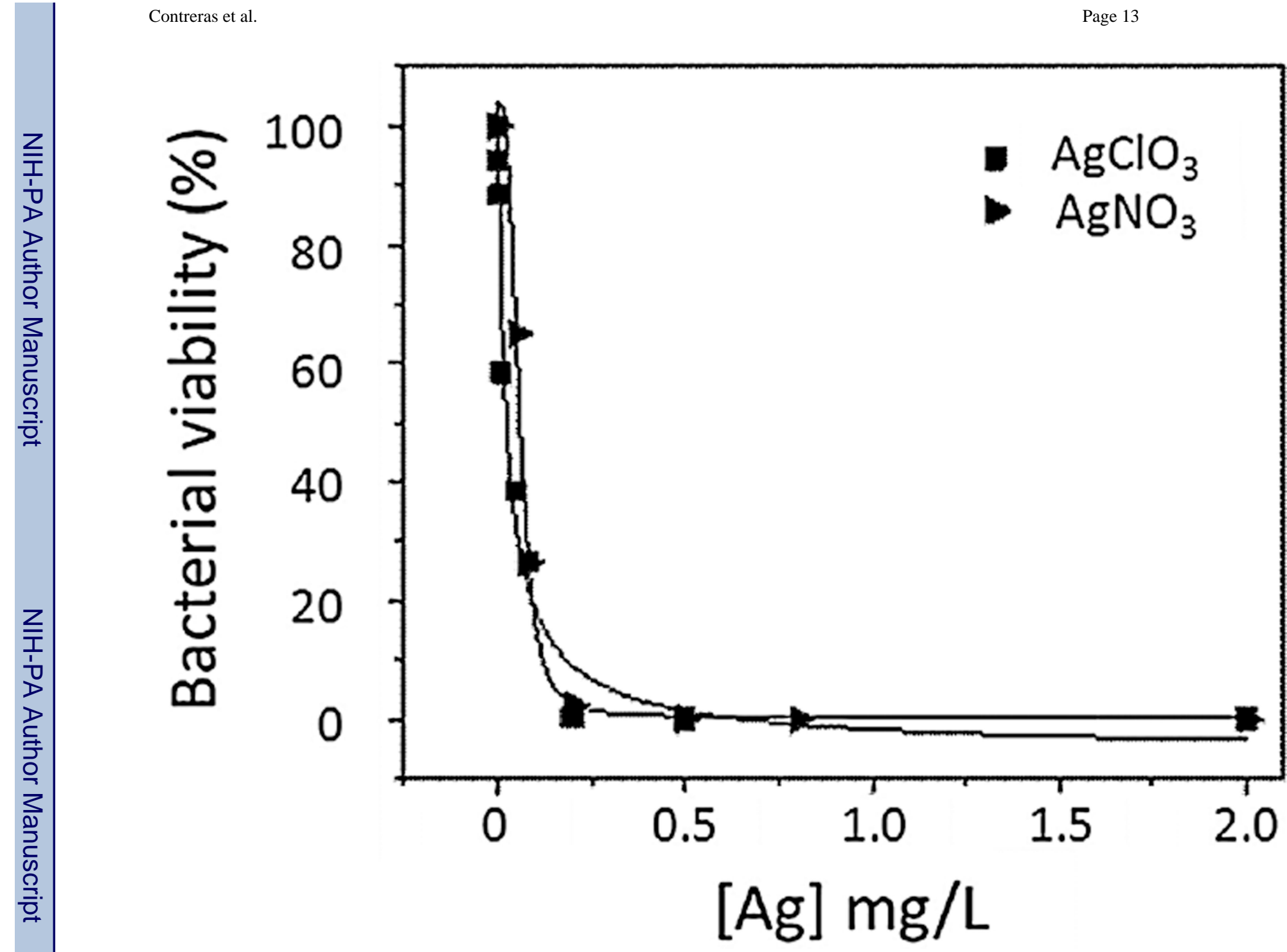

Figure 2.

The 24-h dose-dependent viability curve for Escherichia coli exposed to 2 silver ion sources, $\mathrm{AgClO} 4$ and $\mathrm{AgNO} 3$. The median lethal dose for $\mathrm{AgClO} 4$ was $0.02 \mathrm{mg} \mathrm{Ag} / \mathrm{L}$, and that for $\mathrm{AgNO} 3$ was $0.06 \mathrm{mg} \mathrm{Ag} / \mathrm{L}$. 


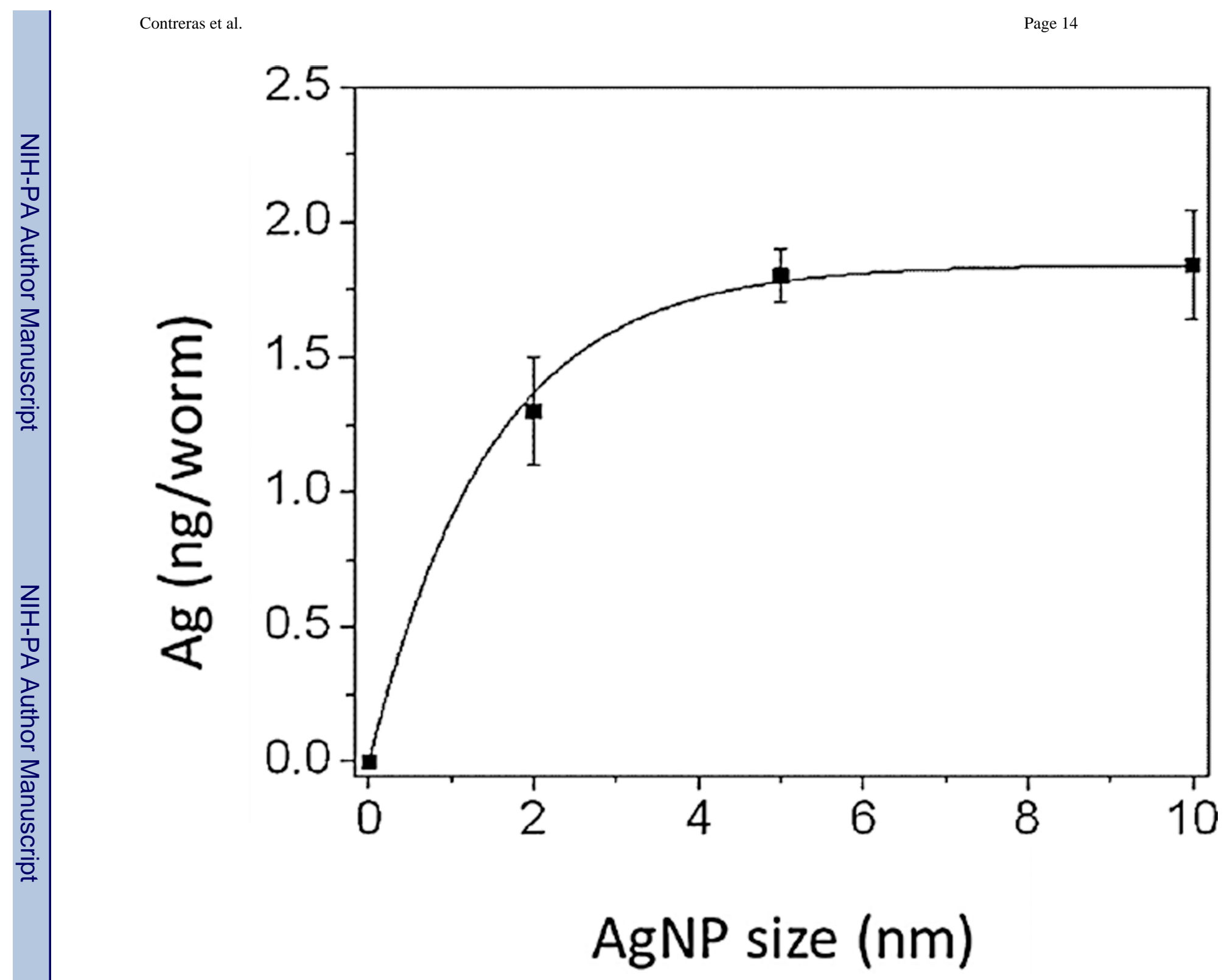

Figure 3.

The uptake profile based on body burden of internalized silver for each Ag nanoparticle (AgNP) using inductively coupled plasma-mass spectrometry. The exposure concentration was $[\mathrm{Ag}]=100 \mathrm{mg} / \mathrm{L}$. Data shown are mean \pm standard error $(n=4)$. 


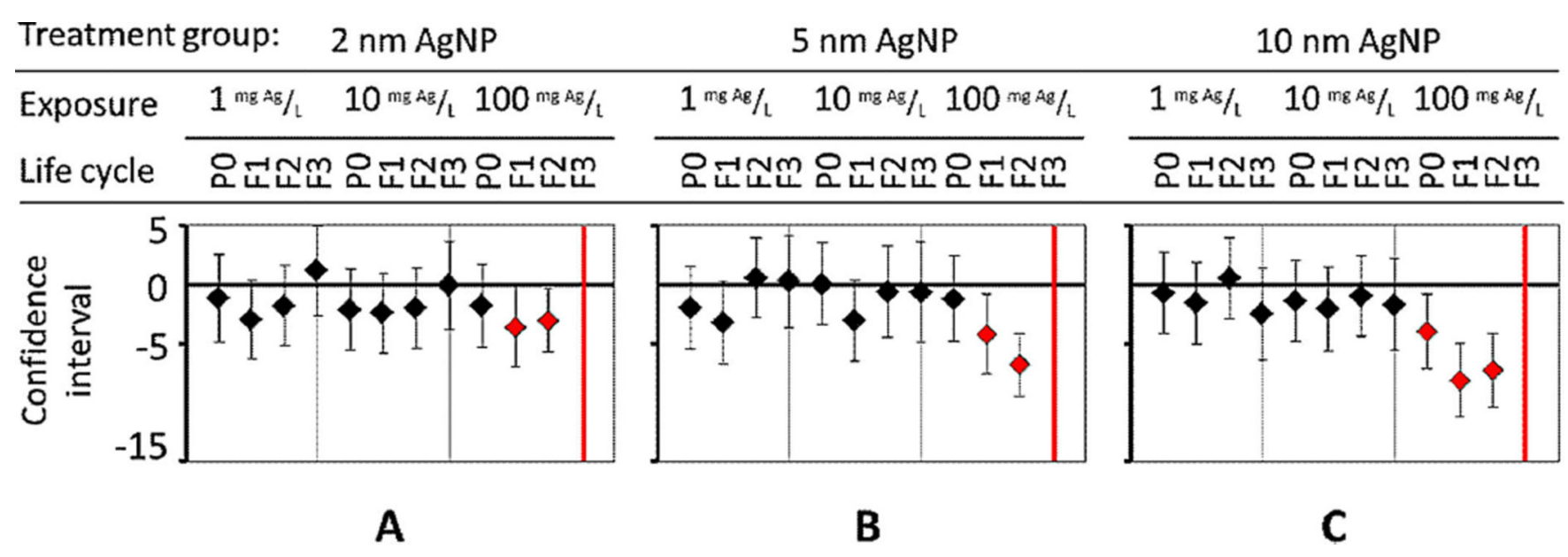

Figure 4.

Lifespan measurement for multiple generations at different concentrations for each treatment of (A) 2-nm, (B) 5-nm, and (C) 10-nm diameter Ag nanoparticles (AgNPs). Adverse effects from exposure to AgNPs were size-dependent. $\mathrm{P}_{0}=$ parent generation; $\mathrm{F}_{1}=$ first-generation progeny; $F_{2}=$ second-generation progeny; $F_{3}=$ third-generation progeny. [Color figure can be viewed in the online issue which is available at wileyonlinelibrary.com] 


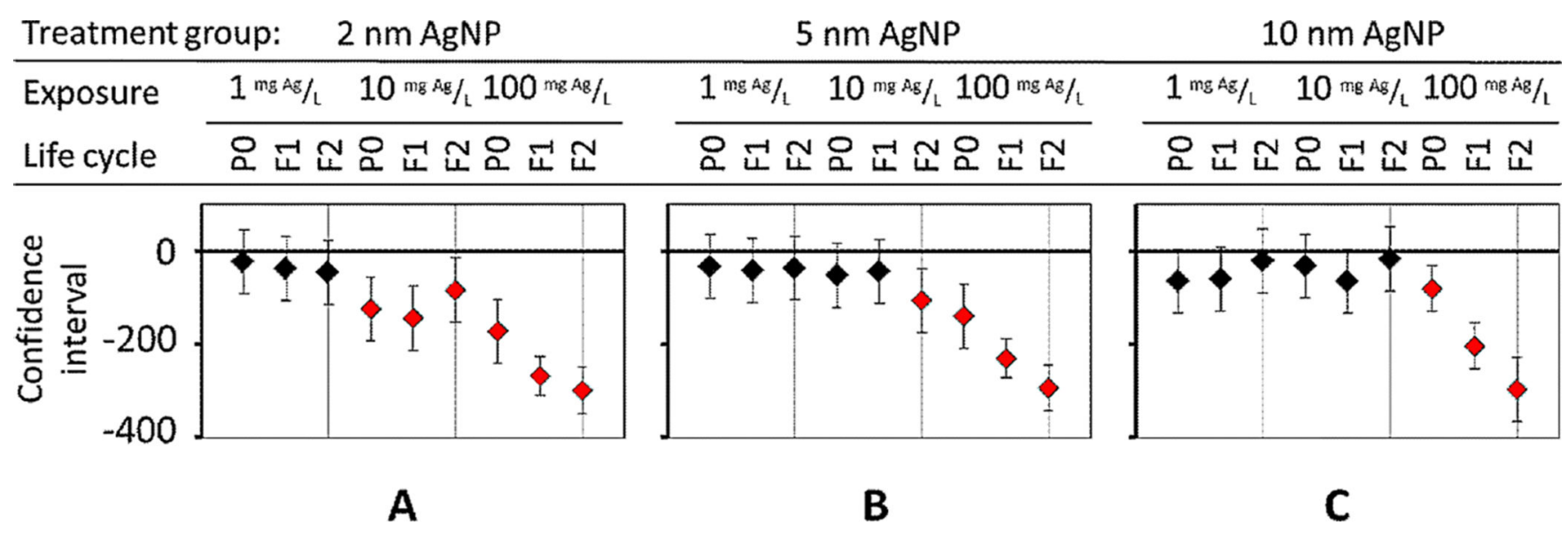

Figure 5.

Brood size significantly decreases over multiple generations after exposure to $\mathrm{Ag}$ nanoparticles (AgNPs) of (A) 2-nm, (B) 5-nm, and (C) 10-nm diameter. Size-dependent toxicity is evident at higher exposure concentrations. $\mathrm{P}_{0}=$ parent generation; $\mathrm{F}_{1}=$ firstgeneration progeny; $\mathrm{F}_{2}=$ second-generation progeny; $\mathrm{F}_{3}=$ third-generation progeny. [Color figure can be viewed in the online issue which is available at wileyonlinelibrary.com] 


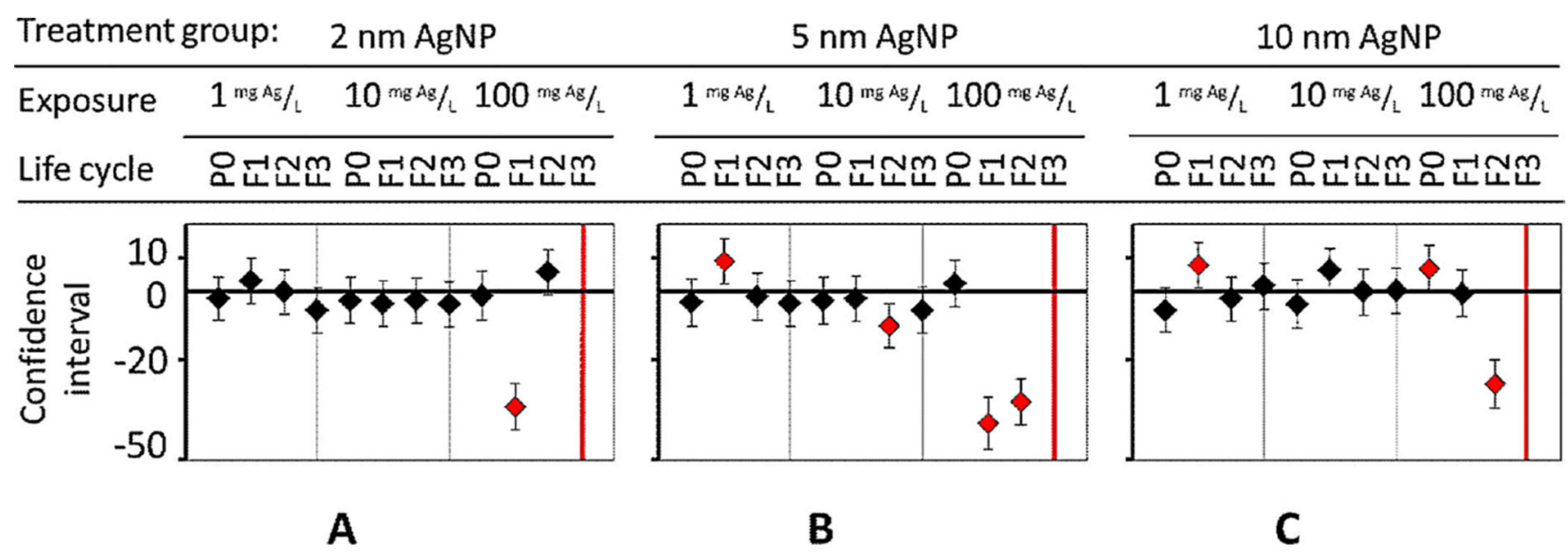

Figure 6.

Length in nematodes was measured in the present multigeneration study using a worm tracker. Quantitative analysis showed significant changes in length and development, but no size dependence after exposure to (A) 2-nm, (B), 5-nm, and (C) 10-nm diameter Ag nanoparticles (AgNPs) was immediately noted. $\mathrm{P}_{0}=$ parent generation; $\mathrm{F}_{1}=$ first-generation progeny; $F_{2}=$ second-generation progeny; $F_{3}=$ third-generation progeny. [Color figure can be viewed in the online issue which is available at wileyonlinelibrary.com] 


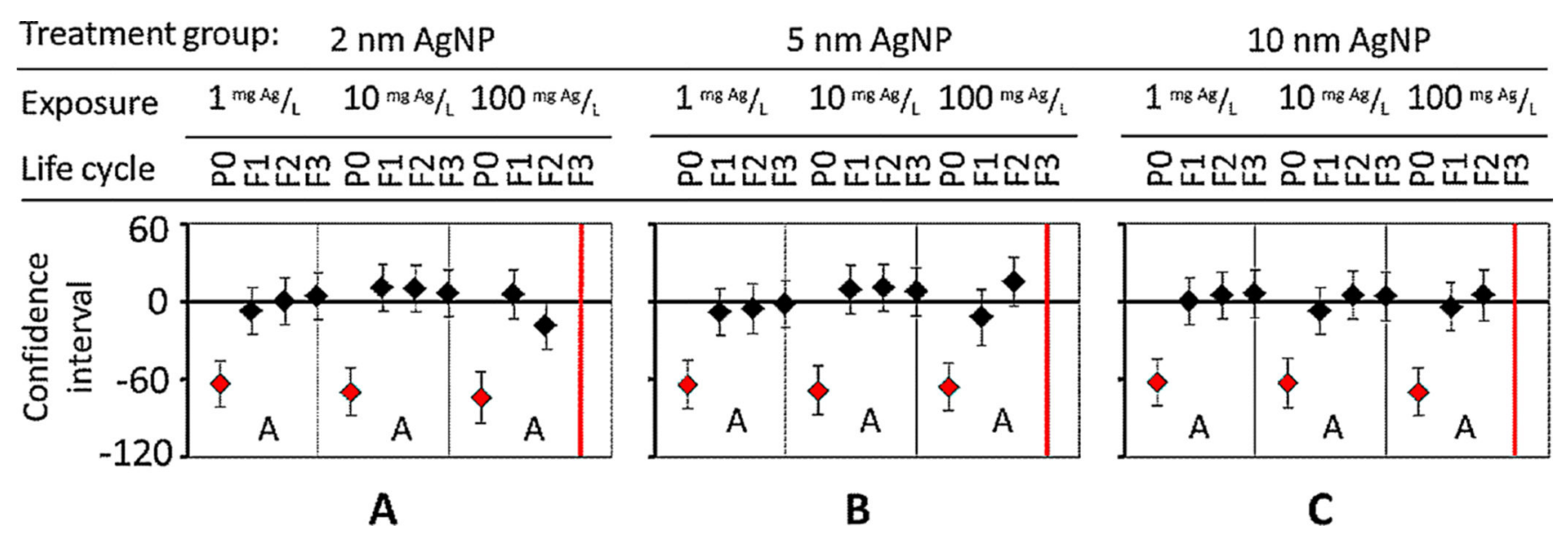

Figure 7.

Flex measurements in nematodes quantifying the number of times the body bends. After exposure to Ag nanoparticles (AgNPs) of (A) 2-nm, (B) 5-nm, and (C) 10-nm diameter for multiple generations, an adverse effect was seen in parent $\left(\mathrm{P}_{0}\right)$ nematodes before acclimation. $\mathrm{P}_{0}=$ parent generation; $\mathrm{F}_{1}=$ first-generation progeny; $\mathrm{F}_{2}=$ second-generation progeny; $\mathrm{F}_{3}=$ third-generation progeny. [Color figure can be viewed in the online issue which is available at wileyonlinelibrary.com] 


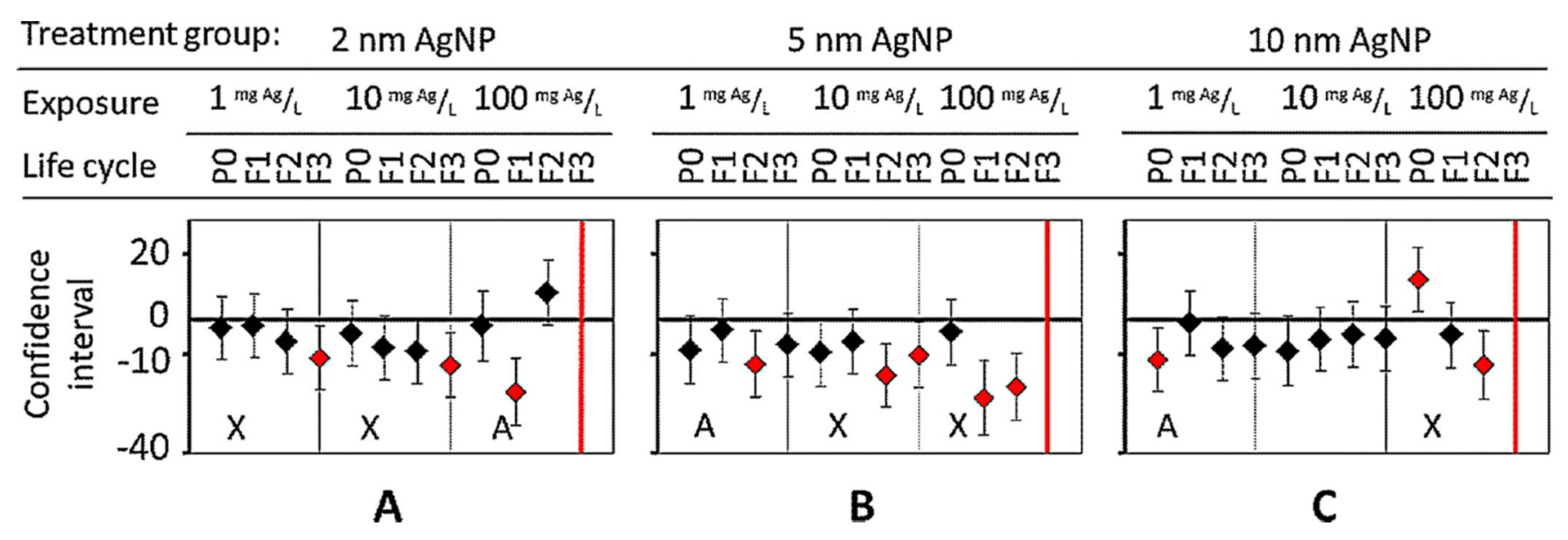

Figure 8.

Amplitude measurement of nematode sinusoidal movement after exposure to different $\mathrm{Ag}$ nanoparticle (AgNP) treatments of (A) 2-nm, (B) 5-nm, and (C) 10-nm diameter AgNP. $\mathrm{P}_{0}$ $=$ parent generation; $F_{1}=$ first-generation progeny $; F_{2}=$ second-generation progeny; $F_{3}=$ third-generation progeny. [Color figure can be viewed in the online issue which is available at wileyonlinelibrary.com] 


\begin{tabular}{|c|c|c|c|c|c|}
\hline \multicolumn{2}{|c|}{ Treatment group: } & $2 \mathrm{~nm}$ AgNP & \multicolumn{2}{|r|}{$5 \mathrm{~nm}$ AgNP } & $10 \mathrm{~nm}$ AgNP \\
\hline Exposure & $1 \mathrm{mg} A g / \mathrm{L}$ & $10 \mathrm{mg} \mathrm{Ag} / \mathrm{L} \quad 100 \mathrm{mg} \mathrm{Ag} / \mathrm{L}$ & $1 \mathrm{mg} A \mathrm{~B} / \mathrm{L}$ & $10 \mathrm{mg} \mathrm{AB}_{\mathrm{g}} \mathrm{L} \quad 100 \mathrm{mg} \mathrm{AB} / \mathrm{L}$ & $10 \mathrm{mg} \mathrm{Ag} / \mathrm{L} \quad 100 \mathrm{mg} \mathrm{AB} / \mathrm{L}$ \\
\hline Life cycle & 윰너 & 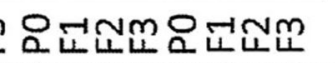 & 윰퍼네 & 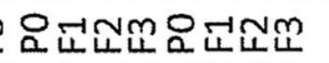 & 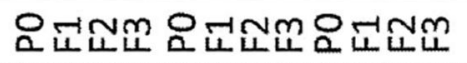 \\
\hline
\end{tabular}

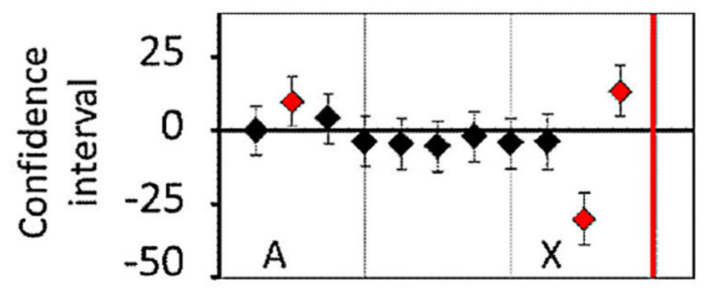

A

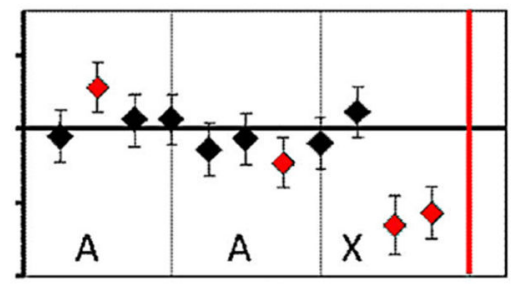

B

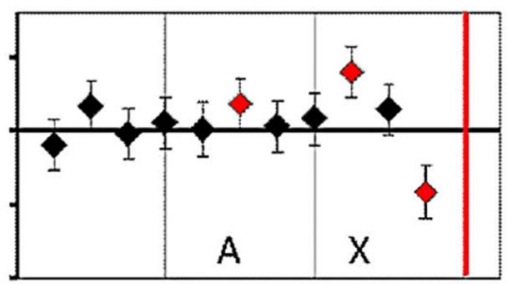

C

Figure 9.

Wavelength measurement of nematode sinusoidal movement at each generation and after treatment of (A) 2-nm, (B) 5-nm, and (C) 10-nm diameter Ag nanoparticles (AgNPs).

[Color figure can be viewed in the online issue which is available at wileyonlinelibrary.com] 
Treatment group: $2 \mathrm{~nm} \mathrm{AgNP} \quad 5 \mathrm{~nm} \mathrm{AgNP} \quad 10 \mathrm{~nm} \mathrm{AgNP}$

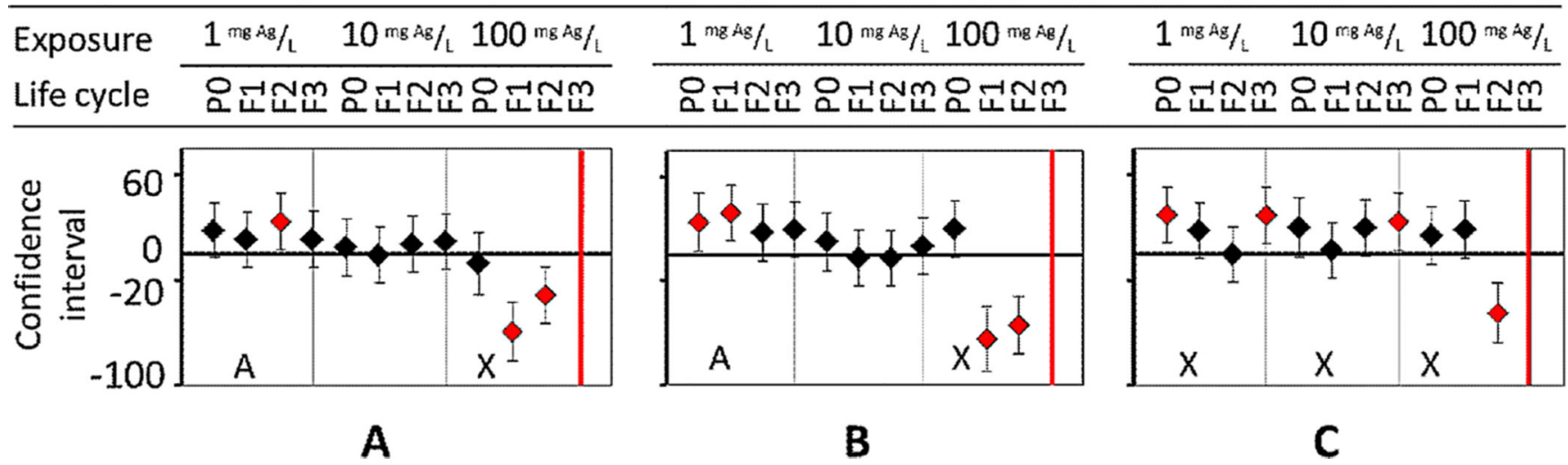

Figure 10.

The velocity of nematodes changed significantly after exposure to treatment of (A) 2-nm, (B) 5-nm, and (C) 10-nm diameter Ag nanoparticles (AgNPs). $\mathrm{P}_{0}=$ parent generation; $\mathrm{F}_{1}=$ first-generation progeny; $F_{2}=$ second-generation progeny; $F_{3}=$ third-generation progeny.

[Color figure can be viewed in the online issue which is available at wileyonlinelibrary.com] 


\section{Table 1}

Bacterial (OP50 Escherichia coli) viability after 24-h exposure to nanoparticles or silver salts ${ }^{a}$

\begin{tabular}{lccc}
\hline Sample & Ag $(\mathbf{m g} / \mathbf{L})$ & Log CFU & $p$ value \\
\hline Control & 0 & 9.0 & - \\
$2 \mathrm{~nm}$ & 1 & 9.0 & 0.78 \\
& 10 & 9.0 & 0.93 \\
& 100 & 8.9 & 0.08 \\
$5 \mathrm{~nm}$ & 1 & 9.1 & 0.73 \\
& 10 & 9.1 & 0.76 \\
& 100 & 8.9 & 0.12 \\
$10 \mathrm{~nm}$ & 1 & 9.0 & 0.18 \\
& 10 & 9.0 & 0.17 \\
& 100 & 9.1 & 0.67 \\
\hline
\end{tabular}

${ }^{a}$ No silver nanoparticles showed antimicrobial activity. With median lethal dose (LD50) values of $0.06 \mathrm{mg} \mathrm{Ag} / \mathrm{L}$ for $\mathrm{AgNO} 3$ and $0.02 \mathrm{mg} \mathrm{Ag} / \mathrm{L}$ for $\mathrm{AgClO}_{4}$ (Figure 2), toxicity of silver ions was evident. However, no effects were observed with silver nanoparticles up to $100 \mathrm{mg} \mathrm{Ag} / \mathrm{L}$ compared with untreated control $(p<0.05)$.

$\mathrm{CFU}=$ colony-forming unit. 